of artificial eyes in Babylonian times has recently been proved by the discovery of a cuneiform inscription of about 1600 B.c., in which 22 artificial eyes, 9 of agate and 13 of chalcedony, are mentioned. In ancient Greece statues were often provided with artificial eyes, Pheidias's statue of Athena being a celebrated example. In ancient Rome the faber ocularius, or maker of artificial eyes, existed as well as the medicus ocularius, who was a favourite subject for contemporary satirists, especially Martial. There is no definite description of artificial eyes to replace those lost by disease or accident before the middle of the sixteenth century, when they are mentioned by Ambroise Paré, but, as Dr. Bruce points out, the terms in which he speaks of them do not indicate that they were an innovation at that time.

\section{The Development Commission}

THE twenty-ninth report of the Development Commissioners, for the year ending March 31, 1939, has just been published (H.M. Stationery Office. 2s.). The total sum recommended for the fund was

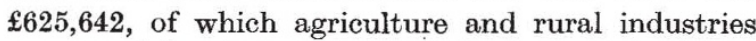
accounted for $£ 579,480$, and fisheries and harbours $£ 46,162$. These grants, particularly in the latter case, were rather smaller than in the previous year, when the amounts were $£ 608,911$ and $£ 131,555$ respectively. A short section describes the subject of study, size of staff and total sums available for expenditure at each of the agricultural research institutes in receipt of grants from the Fund, but details of their work are supplied in other publications. Results accruing from grants are necessarily difficult to assess, but it must be remembered that it is largely through her research institutes that Great Britain maintains such a close touch with agricultural science throughout the world, and has been able to assist in Empire development through supplying trained men.

As regards rural industries, the greater part of the sum allocated has taken the form of grants to the Rural Industries Bureau. The latter exists both to help the craftsmen for their own sakes and to maintain the village workshop for the sake of the country. By its advisory service and the introduction of improved equipment and methods of business it is hoped to secure the interest of the younger generation in industries of vital importance to the farmer. Investigations undertaken by the Fishery Departments are largely carried out under schemes adopted by the International Council for the Exploration of the Sea. Both the English and Scottish share of the investigations receive support from the Fund, and grants have also been made for research on freshwater fisheries.

\section{Colorimetry of Electric Discharge Lamps}

IT is claimed in the G.E.C. Journal of February that during last year very satisfactory progress was made in developing various types of technique for improving electric discharge lamps. Unsolved problems in heterochromatic photometry and colorimetry previously stood in the way. The problem was complicated by the practical application of fluorescent discharge lamps to domestic and other forms of interior lighting. This made it necessary to measure the colour-rendering properties of the light sources in a way distinct from their colour. Although nonselectively reflecting surfaces or fabrics, such as 'whites' or 'greys', will have the same coloured appearances when illuminated by light from such sources, since reflection by these surfaces produces no change in the spectral energy distribution of the light, the coloured appearance of selectively reflecting surfaces, such as dyed fabrics, may be quite different. Therefore, although the colour of these two light sources is the same, their colour-rendering properties are different, and it is this latter property which it is desired to measure.

Two types of measurement are made: $(a)$ the determination of the most desirable colour-rendering properties of light sources when performing different tasks at different illuminations (this involves major research into chromaticity scales under different observational conditions); (b) the recording of the spectral luminosity distribution of light sources already established as satisfactory for particular purposes, so that the manufacture of such lamps can be controlled in a manner to ensure uniformity of colourrendering properties of the commercial lamps or fittings. These measurements are carried out by visual photometric measurements of spectral luminosity made, in turn, through a series of spectral filters which transmit light only within defined wavelength limits. This involves a comparatively simple technique which can be undertaken commercially with photometric apparatus. For differentiating and defining the colour-rendering properties of many electric discharge lamps, this method is not sufficiently sensitive. One recent method, which is being used to define the luminosity distribution throughout the spectrum, utilizes physical photometric methods of measuring the relative luminosity in eight suitably chosen adjacent spectral bands, extending throughout the physical spectrum.

\section{Trench Fever}

IN his inaugural thesis (These de Paris, No. 870 ; 1939), Dr. Robert Schapiro remarks that since the War of 1914-18, during which trench fever was very prevalent both on the French and Italian fronts as well as in Salonica and Mesopotamia, endemic cases have been reported in the south of France and Russia. It is also probable that many cases have passed unrecognized. Reports received from Spanish doctors living in their own country or as refugees in France indicate that there has been an outbreak of the disease in Spain, although Schapiro has been unable to obtain confirmation of this from other sources. The possibility, however, of a return of the disease must be recognized in view of the fact that defective hygienic conditions, and particularly the presence of lice among the troops, favour the spread of trench fever.

Moreover, the risk of its occurrence is increased by the transfer last autumn of German troops from east to west, as the disease is undoubtedly more 